\title{
Absorption and emission of water vapor from the bark of teak (Tectona grandis), a deciduous tree, in a tropical region during the dry season
}

\author{
Hiroyuki Matsunaga ${ }^{1}$, Naoko Matsuo ${ }^{1}$, Takahisa Nakai ${ }^{1}$, Natsuko Yoshifuji ${ }^{2}$, Nobuaki Tanaka ${ }^{3}$, \\ Katsunori Tanaka ${ }^{4}$ and Chatchai Tantasirin ${ }^{5}$ \\ ${ }^{1}$ Graduate School of Bioresources, Mie University, Japan \\ ${ }^{2}$ Forestry and Forest Products Research Institute, Japan \\ ${ }^{3}$ The University of Tokyo Hokkaido Forest, The University of Tokyo Forests, Graduate School of Agricultural and \\ Life Sciences, The University of Tokyo, Japan \\ ${ }^{4}$ GRID INC., Japan \\ ${ }^{5}$ Faculty of Forestry, Kasetsart University, Thailand
}

\begin{abstract}
:
Changes in stem circumference (SC) were observed in teak (Tectona grandis) in a tropical region during the dry season after tree-ring formation had stopped. We hypothesized that these SC changes were caused by water absorption and emission from the outer bark surface. To test this hypothesis, we measured SC, heat pulse velocity (HPV), and leaf number using time series images in a teak tree plantation in northern Thailand. We also performed laboratory experiments to observe changes in the weight and thickness of teak bark blocks under various vapor pressure conditions. Increases in teak tree SC were observed after rainfall during the dry season, when defoliation was almost complete and HPV was low. The weight and thickness of the bark blocks, on which all surfaces other than the outer bark were sealed, varied with water vapor content. These results suggest that water vapor absorption and emission through the outer bark surface can affect SC during the dry season. However, SC continued to increase after the vapor pressure deficit increased, and decreased more rapidly in the tree with higher HPV, suggesting that water exchange between the xylem and inner bark also contributes to changes in SC.
\end{abstract}

KEYWORDS defoliation; inner bark; outer bark; sap flow; stem circumference fluctuation; tropical seasonal forest

\section{INTRODUCTION}

Tropical seasonal forests, which are distributed in tropical monsoon climate regions and occupy about $43 \%$ of the total area of tropical forests (Food and Agriculture Organization, 2001), are characterized by high net ecosystem productivity and carbon reserves. The inter-annual variability of the Asian tropical monsoon is predicted to increase, along with the amount of monsoon rainfall, with increasing greenhouse gas levels (Meehl and Arblaster, 2003). A deeper understanding of the water dynamics of tropical seasonal forests is essential for predicting the contribution of these forests to water cycle fluctuations under a changing climate. Teak (Tectona grandis L. f.) is a dominant deciduous tree species in tropical seasonal forests. Teak trees in a plantation in northern Thailand have been reported to drop their leaves during the dry season in response to decreases in soil water content (Yoshifuji et al., 2006, 2011, 2014). Thus, seasonal fluctuations of teak tree water status predict the water dynamics of tropical seasonal forests in response to seasonal changes in Asian tropical monsoon conditions.

Tree bark consists of outer and inner bark, and protects the inner tissues of the tree (Angyalossy et al., 2016). Photosynthetic products are transported via inner bark (phloem) within the phellem (cork tissue) (Angyalossy et al., 2016). Water storage in the inner bark contributes strongly to maintaining the water content of xylem vessels (Zweifel et al., 2000). When cavitation occurs in xylem vessels under dry conditions, water stored in the inner bark moves into xylem vessels to eliminate cavitation (Zweifel et al., 2000; Pfautsch et al., 2015). Fluctuations in water storage in turn cause fluctuations in stem volume through the expansion and contraction of phloem parenchymal tissues. These fluctuations in stem diameter can be attributed to changes in inner bark volume, which differ from hypertrophic growth (Brough et al., 1986; Zweifel and Häsler, 2000). Thus, measurements of changes in tree diameter obtained using a dendrometer have been used to assess stem water conditions in many studies (Zweifel and Häsler, 2000; Zweifel et al., 2000, 2005, 2007, 2016; Steppe et al., 2006, 2015).

Stem water deficits occur when the vapor pressure deficit (VPD) is high and soil water content is low (Zweifel et al., 2005, 2016), which suggests that soil water absorption by roots and transpiration by leaves are the major factors affecting the swelling and shrinking of the stem. Previous studies have assumed the absence of water absorption through the bark surface. The outer bark is often assumed to have low water permeability (e.g. Groh et al., 2002; Angyalossy et al., 2016). However, some studies have con-

Correspondence to: Naoko Matsuo, Graduate School of Bioresources, Mie University, 1577 Kurimamachiya, Tsu, Mie 514-8507, Japan. E-mail: naoko@bio.mie-u.ac.jp 
firmed that water permeates the xylem through the outer bark. For example, embolisms in xylem vessels were eliminated when a redwood branch was placed in a fog chamber, suggesting that water permeated the xylem through the outer bark (Earles et al., 2016).

Therefore, to clarify whether water exchange occurs through the outer bark of teak trees in a tropical seasonal forest, we measured the response of stem circumference (SC) to rainfall events during the dry season, when leaf transpiration and sap flow are inactive. To confirm that water exchange occurs through the outer bark, we also observed changes in the water content and thickness of bark blocks sampled from a teak tree that were equilibrated with water vapor under various VPD conditions. Based on these field observations and laboratory experiments, we explored whether teak trees exchange water through their outer bark.

\section{METHODS}

\section{Study site, plant material, and environmental condi-} tions

This study was conducted in an even-aged teak stand planted in 1968 at the MaeMoh plantation in Lampang Province, northern Thailand $\left(18^{\circ} 25^{\prime} \mathrm{N}, 9^{\circ} 43^{\prime} \mathrm{E}, 380 \mathrm{~m}\right.$ a.s.l.). The annual mean temperature at the study site is $25.4^{\circ} \mathrm{C}$ and the mean precipitation is $1361 \mathrm{~mm} \mathrm{yr}^{-1}$ (20012012). In this region, precipitation is affected by the Asian monsoon, and occurs mainly during the wet season from around May to October. Teak is a tropical deciduous hardwood species that produces leaves at the beginning of the wet season and drops them completely in the late dry season (Yoshifuji et al., 2006).

Precipitation was measured every 10 min using a tipping-backet rain gauge (No. 34T; Ohta Keiki, Tokyo, Japan) in an open plot at the study site. Air temperature and relative humidity were measured every $10 \mathrm{~min}$ using an aspirated psychrometer (MS-801 or HMP115a; Vaisala, Helsinki, Finland) at a height of $39 \mathrm{~m}$ on the observation tower to calculate VPD. Volumetric soil water content $(\theta)$ was measured near the tower at depths of 10, 20, 40, and $60 \mathrm{~cm}$ every $10 \mathrm{~min}$ using a time-domain reflectometer (CS615; Campbell Scientific, Logan, USA). Relative soil water content $(\Theta)$ was calculated as:

$$
\Theta=\frac{\theta_{0-60 \_t}-\theta_{0-60 \_ \text {min }}}{\theta_{0-60 \_ \text {max }}-\theta_{0-60 \_ \text {min }}}
$$

where $\theta_{0-60}$ is the arithmetic mean of $\theta$ at depths of 10, 20, 40 , and $60 \mathrm{~cm} ; \theta_{0-60 t}$ is $\theta_{0-60}$ at time $t$; and $\theta_{0-60 \max }$ and $\theta_{0-60 \min }$ are the maximum and minimum values of $\theta_{0-60}^{-}$over 2 years (January 2014-December 2015), respectively. We defined the period when $\Theta$ was below 0.2 as the dry season, in accordance with previous studies (Yoshifuji et al., 2011, 2014), and the period of concentrated rainfall was designated the wet season.

\section{Stem circumference, sap flow, and canopy leaf state measurements}

$\mathrm{SC}$ and sap flow were measured in two teak trees $(\mathrm{C} 1$ and C3) growing near the tower. Height and diameter at breast height were measured at $23.8 \mathrm{~m}$ and $32.4 \mathrm{~cm}$ for $\mathrm{C} 1$ and $26.6 \mathrm{~m}$ and $36.6 \mathrm{~cm}$ for C3 in April 2014. SC (mm) was measured hourly at a height of $1.2 \mathrm{~m}$ above the ground surface for C1 and C3 from November 2013 to June 2016 using a band dendrometer (DRL26A; EMS Brno, Brno, Czech Republic). In this study, the value of SC recorded on April 1, 2014, was recalibrated to zero, and the accumulated amount of daily increase or decrease in SC relative to this value was defined as stem circumference fluctuation (SCF; mm).

Heat pulse velocity (HPV; $\mathrm{cm} \mathrm{h}^{-1}$ ) was measured for C1 and C3 every 20 min from October 2012 to July 2015 using a heat ratio-based sensor (SFM1; ICT International, Armidale, Australia) with two detection points; we used the inner point, which continuously recorded data throughout the dry season. The installation of the SFM device on the studied trees was described in detail by Tanaka et al. (2017). To analyze changes in HPV for each tree, we calculated the relative HPV for each tree as follows:

$$
H P V_{-} N=\frac{H P V_{t}-H P V_{\text {min }}}{H P V_{\text {max }}-H P V_{\text {min }}}
$$

where $H P V_{t}$ is the hourly mean HPV at time $t$ and $H P V_{\max }$ and $H P V_{\text {min }}$ are the maximum and minimum values of hourly mean HPV, respectively, from April 2014 to June 2015 for each tree.

Time series images of the canopies of C1 and C3 were recorded weekly from September 2014 to March 2015 using time lapse cameras (Brinno, Tokyo, Japan) installed on the tower. We randomly selected 30 live leaves from each canopy in the initial images and tracked changes in their number during the dry season to estimate when defoliation occurred for each tree.

\section{Bark water adsorption and desorption experiments}

Laboratory experiments were conducted to assess bark water adsorption (BWA) and bark water desorption (BWD) using bark samples, including both the outer and inner bark layers, collected from the bottom of one teak tree at the study site (39.8 cm in diameter). The bark samples were cut into 16 small blocks ( $30 \mathrm{~mm}$ height $\times 30 \mathrm{~mm}$ width) and all surfaces except the outer bark were sealed with epoxy resin (AR-R30; Huntsman, Kobe, Japan) to prevent water vapor exchange through those surfaces. Bark blocks were then oven-dried at $105^{\circ} \mathrm{C}$ for $24 \mathrm{~h}$ (DK400T; Yamato Scientific, Tokyo, Japan). The respective average weight and thickness of the dried bark were $7.46 \mathrm{~g}$ and $11.80 \mathrm{~mm}$ in the BWA experiment and $7.32 \mathrm{~g}$ and $11.72 \mathrm{~mm}$ in the BWD experiment, respectively. In the BWA experiment, dried bark blocks were sealed into the chamber individually to maintain constant temperature $\left(20^{\circ} \mathrm{C}\right)$ and VPD $(20.9,15.7$, $10.7,5.8$, or $1.6 \mathrm{hPa}$ ). Four blocks were maintained at a VPD of $1.6 \mathrm{hPa}$, and three blocks were maintained at each of the other VPD values. Changes in the fresh weight and thickness of each bark block were measured using an electronic balance (LIBROR AEX-180; Shimadzu, Kyoto, Japan) and a digimatic electronic caliper (Mitutoyo Corporation, Kanagawa, Japan), respectively. These measurements were repeated until the weight of the block reached a constant value. In the BWD experiment, the dried bark blocks were equilibrated with water vapor in a desiccator at $1.6 \mathrm{hPa}$ of VPD for 98 days and then sealed into chambers with constant temperature $\left(20^{\circ} \mathrm{C}\right)$ and $\operatorname{VPD}(20.9,15.7$, 
10.7 , or $5.8 \mathrm{hPa}$ ). Three samples were measured under each humidity condition. Changes in the fresh weight and thickness of each bark block were measured in the same manner as for the BWA experiment. The VPD of each chamber was controlled using the saturated salt solution method (Table SI).

Changes in the fresh weight and thickness of each bark block were estimated using bark moisture content $(u, \%)$ and bark thickness swelling $\left(S_{e}, \%\right)$ as follows:

$$
\begin{gathered}
u=\frac{W_{w}-W_{s}}{W_{s}} \\
S_{e}=\frac{T_{w}-T_{s}}{T_{s}}
\end{gathered}
$$

where $W_{w}$ and $T_{w}$ are the fresh weight $(\mathrm{g})$ and thickness (mm) of the bark block, respectively, and $W_{s}$ and $T_{s}$ are its dry weight $(\mathrm{g})$ and dry thickness $(\mathrm{mm})$, respectively. We assumed that the bark blocks reached hydrous equilibrium when the rate of change of $u$ reached $<0.002 \% \mathrm{~h}^{-1}$.

\section{RESULTS AND DISCUSSION}

Response of stem circumference to rain events during the dry season

The SCF of trees $\mathrm{C} 1$ and $\mathrm{C} 3$ increased from late April to the end of September 2014, and then decreased from October until the first rainfall in January 2015, during the

(a)

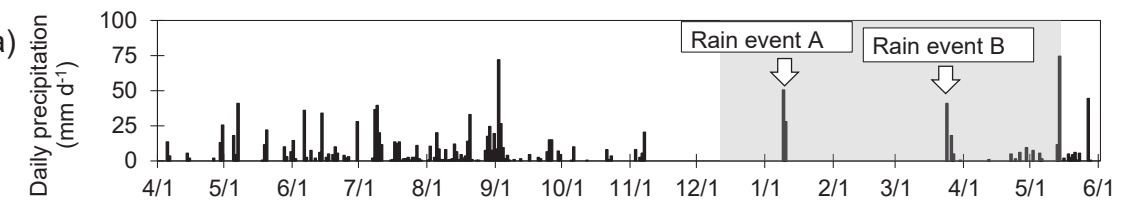

(b)

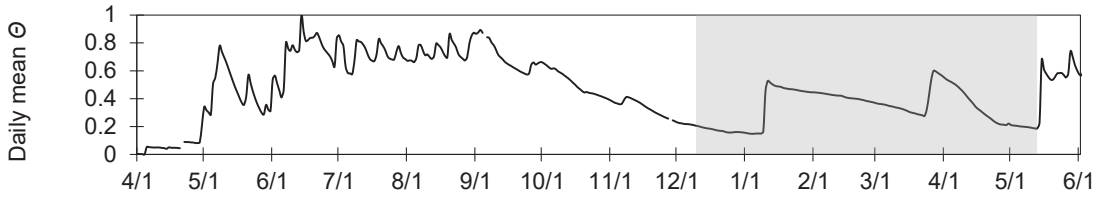

(c)

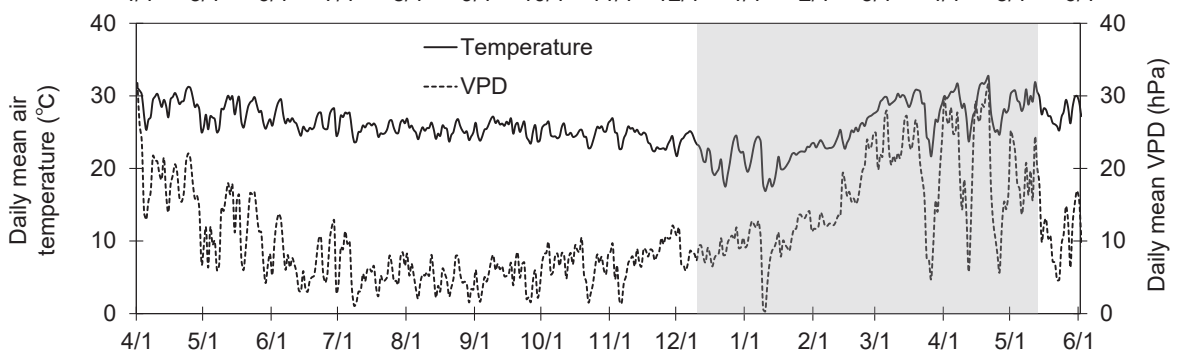

(d)

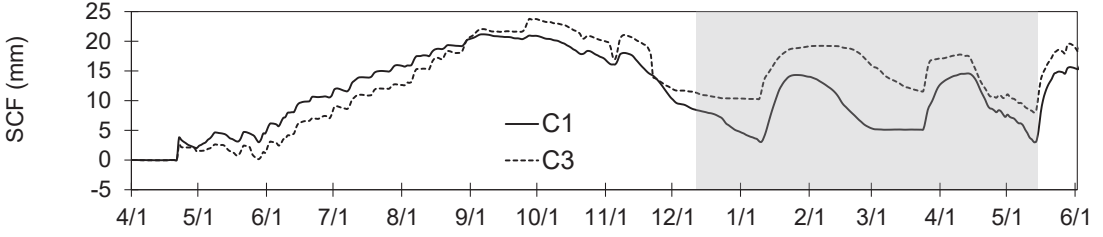

(e)

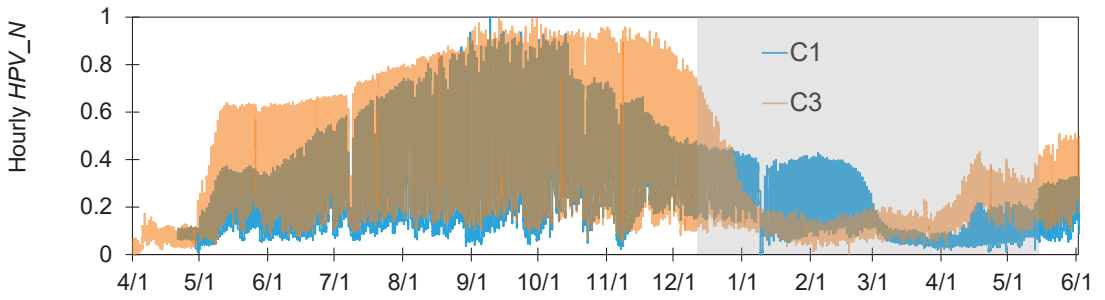

(f)

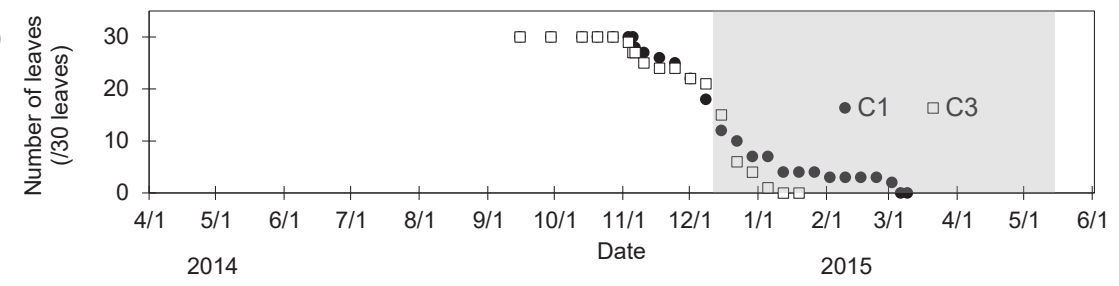

Figure 1. Seasonal patterns of $(\mathrm{a}-\mathrm{c})$ environmental conditions and $(\mathrm{d}-\mathrm{f})$ teak tree parameters for two trees $(\mathrm{C} 1$ and $\mathrm{C} 3)$ at the study site. (a) Daily precipitation; (b) daily mean relative soil moisture content $(\Theta)$; (c) daily mean air temperature and vapor pressure deficit (VPD); (d) stem circumference fluctuation (SCF); (e) hourly relative heat pulse velocity (HPV_N); (f) number of leaves. Gray shading indicates the dry season; white arrows indicate rain events 
dry season, and increased again after two rain events during the dry season (rain events A and B in Figure 1a,d). Microscopic observation of stem microcores sampled from $\mathrm{C} 1$ and $\mathrm{C} 3$ indicated that cambium activity and tree-ring formation had stopped during the dry season in both trees (Matsunaga, unpublished data). Therefore, we conclude that the changes in SC observed during the dry season were not caused by tree ring growth, but by changes in the volume of stem water storage tissue such as inner bark.

Before rain event $\mathrm{A}$, the diurnal range of hourly $H P V \_N$ decreased to less than half of its maximum during the wet season in $\mathrm{C} 1$ and approached its annual minimum in $\mathrm{C} 3$ (Figure 1e). The number of leaves observed in the time series images began to decrease in late October in C3 and in early November in $\mathrm{C} 1$, and defoliation was nearly complete in January in $\mathrm{C} 3$, although a few leaves remained on $\mathrm{C} 1$ (Figure 1f). These results indicate that transpiration was already inactive, at least in $\mathrm{C} 3$, when rain event $\mathrm{A}$ occurred.
Bark moisture adsorption and desorption through the outer bark surface

In the BWA experiment, $u$ and $S_{e}$ increased throughout the experimental period at VPD values of 15.7, 10.7, 5.8, and $1.6 \mathrm{hPa}$, but showed little change at $20.9 \mathrm{hPa}$ (Figure $2 \mathrm{a}, \mathrm{b})$. These factors reached stable values due to hydrous equilibration at each VPD value (Figure 2a, b), which ranged from 1.09 to $20.53 \%$ for $u$ and from -0.45 to $13.24 \%$ for $S_{e}$ (Table I). In the BWD experiment, $u$ and $S_{e}$ decreased immediately after the beginning of the experiment at VPD values of $20.9,15.7,10.7$, and $5.8 \mathrm{hPa}$, and reached stable values more rapidly than in the BWA experiment (Figure 2c, d, Table I). The values of $u$ and $S_{e}$, which reached hydrous equilibrium at each VPD, ranged from 3.49 to $11.22 \%$ and from 2.53 to $4.47 \%$, respectively (Table I). These results indicate that water vapor absorption (emission) through the outer bark surface increased (decreased) the water content and bark thickness. (a)

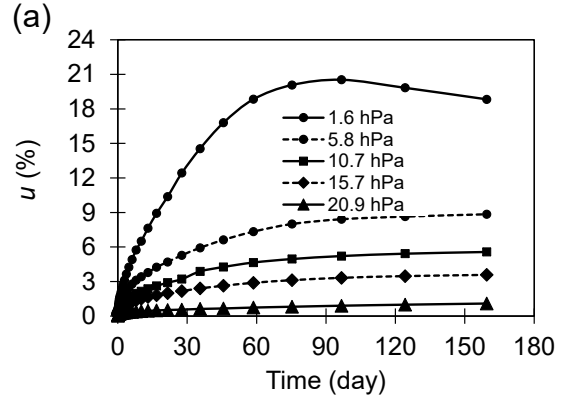

(c)

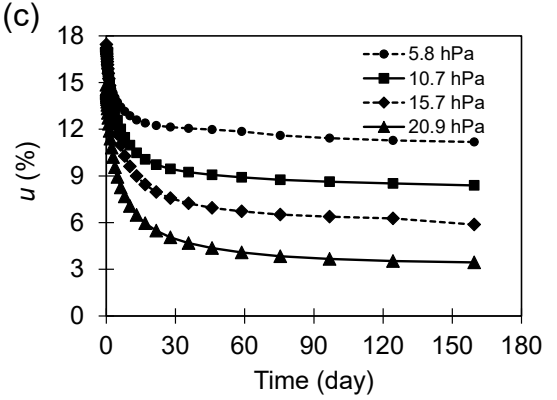

(b)

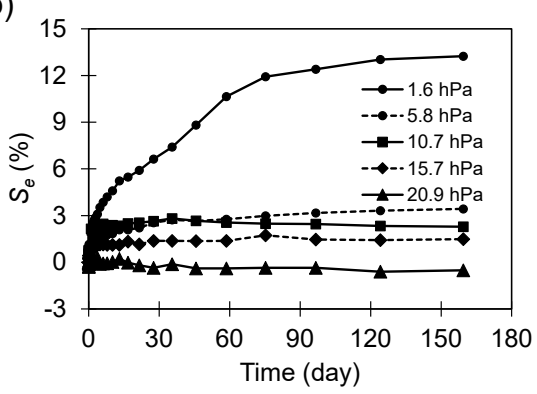

(d)

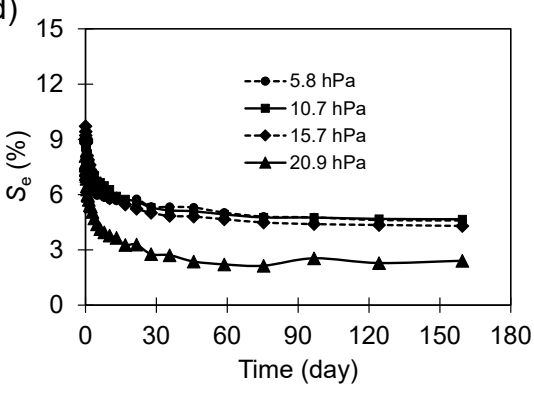

Figure 2. Time series of changes in bark moisture content $(u)$ and bark thickness swelling $\left(S_{e}\right)$ with water vapor pressure during $(\mathrm{a}, \mathrm{b})$ bark water adsorption and $(\mathrm{c}, \mathrm{d})$ bark water desorption experiments performed using teak bark blocks

Table I. Mean values of bark moisture content $(u)$, bark thickness swelling $\left(S_{e}\right)$, and time to reach hydrous equilibrium (days) at each water vapor pressure level in bark water adsorption (BWA) and bark water desorption (BWD) experiments performed using teak bark blocks

\begin{tabular}{|c|c|c|c|c|c|c|}
\hline \multirow{2}{*}{ Experiment } & \multirow{2}{*}{ Parameter } & \multicolumn{5}{|c|}{ Vapor pressure deficit $(\mathrm{hPa})$} \\
\hline & & 1.6 & 5.8 & 10.7 & 15.7 & 20.9 \\
\hline \multirow{3}{*}{ BWA } & $u(\%)$ & 20.53 & 8.84 & 5.57 & 3.58 & 1.09 \\
\hline & $S_{e}(\%)$ & 13.24 & 3.43 & 1.26 & 1.52 & -0.45 \\
\hline & Elapsed time (days) & 97 & 75 & 46 & 10 & $<2$ \\
\hline \multirow{3}{*}{ BWD } & $u(\%)$ & & 11.22 & 8.28 & 6.16 & 3.49 \\
\hline & $S_{e}(\%)$ & & 4.47 & 4.59 & 4.12 & 2.53 \\
\hline & Elapsed time (days) & & 22 & 28 & 36 & 46 \\
\hline
\end{tabular}




\section{Factors influencing SCF after rain events during the} dry season

Daily mean VPD in the study site decreased temporarily to $0.0 \mathrm{hPa}$ during rain event $\mathrm{A}$ (Figure 1a, c). The maximum $S_{e}$ of a bark block in the BWA experiment was $13.24 \%$ at a VPD of $1.6 \mathrm{hPa}$ (Table I). This $S_{e}$ value corresponded to an increase of $9.82 \mathrm{~mm}$ in the circumference of a tree with bark thickness of $11.80 \mathrm{~mm}$; this value was the mean thickness of the bark blocks used in the laboratory experiments and assumed to be equal to the bark thickness of $\mathrm{C} 1$ and $\mathrm{C} 3$, which were of the same age and similar stem diameter. This increase of $9.82 \mathrm{~mm}$ was similar to those in $\mathrm{SC}$ of 11.19 and $8.57 \mathrm{~mm}$, which were observed in $\mathrm{C} 1$ and $\mathrm{C} 3$, respectively, between rain events $\mathrm{A}$ and $\mathrm{B}$ (between $\alpha$ and $\beta$ in Figure 3a, $\mathrm{b}$ ). The daily mean VPD at the study site increased after rain event A, exceeding $20 \mathrm{hPa}$ just before rain event B (Figure 1a, c). The decrease in $S_{e}$ from $13.24 \%$ at a VPD of $1.6 \mathrm{hPa}$ in the BWA experiment to $2.53 \%$ at $20.9 \mathrm{hPa}$ in the BWD experiment corresponded to a decrease in SC of $7.94 \mathrm{~mm}$ for a tree with a mean bark thickness of $11.80 \mathrm{~mm}$. This value was similar to the SCF decrease of 9.20 and $7.65 \mathrm{~mm}$ observed in $\mathrm{C} 1$ and $\mathrm{C} 3$ between the peaks after rain events (between $\beta$ and $\gamma$ and between $\beta$ and $\delta$ in Figure 3a, b). The increase (decrease) in bark thickness in the BWA and BWD experiments was mainly consistent with the increase (decrease) in SC after rain events during the dry season, suggesting that changes in $\mathrm{SC}$ were caused by changes in bark water volume. These changes in SC were observed in the almost completely defoliated teak tree, when HPV was low. These results suggest that water vapor absorption and emission through the outer bark surface can affect changes in SC during the dry season.

However, daily mean VPD dropped to zero during rainfall, and then increased to exceed $10.0 \mathrm{hPa} 5$ days later (Figure 1c). Even after VPD increased, SC continued to increase in both trees (between $\alpha$ and $\beta$ in Figure 3). The $S_{e}$
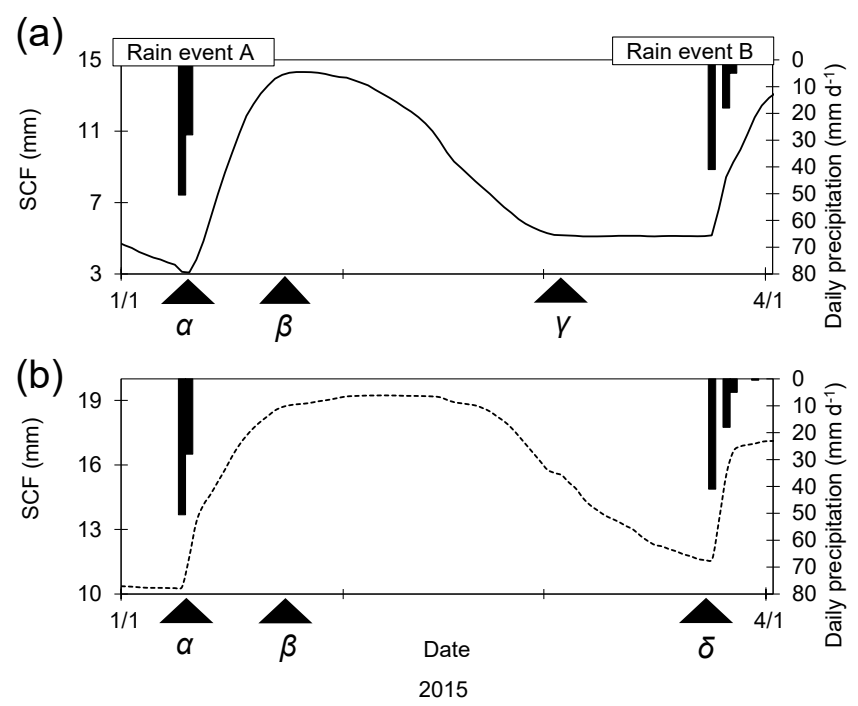

Figure 3. Stem circumference fluctuation (SCF) in teak trees (a) $\mathrm{C} 1$ and (b) $\mathrm{C} 3$ between two rain events during the dry season of the bark block at $10.7 \mathrm{hPa}$ VPD was $1.26 \%$ (Table I), corresponding to an increase of $0.93 \mathrm{~mm}$ in the SC of the tree. Therefore, the increase in SC after rain events cannot be explained only by water vapor absorption through the outer bark surface. During the increase in SC after rain event $\mathrm{A}$ in both trees, soil moisture was relatively high and HPV was not at a minimum (Figure 1b, e). Therefore, water transport from the xylem to the inner bark could have contributed to the increase in stem volume in both trees.

After rain events, SC reached a peak at almost the same time in both trees, and decreased more rapidly in $\mathrm{C} 1$ than in $\mathrm{C} 3$ thereafter (between $\beta$ and $\gamma$ and between $\beta$ and $\delta$ in Figure $3 \mathrm{a}, \mathrm{b})$. Hourly $H P V \_N$ was higher in $\mathrm{C} 1$ than in $\mathrm{C} 3$ after rain event $\mathrm{A}$ (Figure $1 \overline{\mathrm{e}}$ ). The date when the number of leaves reached zero also differed between trees, at 49 days later in $\mathrm{C} 1$ than in C3 (Figure 1f). These differences in sap flow and leaf condition indicate that the amount of water consumed by transpiration after rain event $\mathrm{A}$ was larger in $\mathrm{C} 1$ than in $\mathrm{C} 3$, resulting in a more rapid decrease of $\mathrm{SC}$ in $\mathrm{C} 1$ than in $\mathrm{C} 3$. Therefore, water transport from the inner bark to the xylem appears to have contributed to a decrease in stem volume, even in the dry season.

The results of our field observations and laboratory experiments indicate that teak tree SCF after rain events during the dry season can be attributed to changes in bark thickness caused by water content changes, and that changes in bark water content may be caused by the absorption and emission of water vapor through the outer bark surface and water exchange between the xylem and the inner bark associated with sap flow.

\section{ACKNOWLEDGMENTS}

This study was supported by Japan Society for the Promotion of Science KAKENHI grants (Nos. 24310018 and 26304004). We thank the Forestry Faculty of Kasetsart University and the Thai Forest Industry Organization for their support. Dr. Takaharu Kameoka, Dr. Yoshiko Kosugi, and Dr. Hisashi Abe provided research advice.

\section{SUPPLEMENTS}

Table SI. Chemical composition of salts used in the saturated salt solution method to maintain relative humidity $(\mathrm{RH})$ and vapor pressure deficit (VPD) at saturation at $20^{\circ} \mathrm{C}$.

\section{REFERENCES}

Angyalossy V, Pace MR, Evert RF, Marcati CR, Oskolski AA, Terrazas T, Kotina E, Lens F, Mazzoni SC, Angeles G, Machado SR, Crivellaro A, Rao KS, Junikka L, Nikolaeva N, Baas P. 2016. IAWA list of microscopic bark features. IAWA Journal 37: 517-615. DOI: 10.1163/2294193220160151.

Brough DW, Jones HG, Grase J. 1986. Diurnal changes in water content of the stems of apple trees, as influenced by irrigation. Plant, Cell Environment 9: 1-7. DOI: 10.1111/j.13653040.1986.tb01716.x. 
Earles JM, Sperling O, Silva LCR, Mcelrone AJ, Brodersen CR, North MP, Zwieniecki MA. 2016. Bark water uptake promotes localized hydraulic recovery in coastal redwood crown. Plant, Cell and Environment 39: 320-328. DOI: 10.1111/pce.12612.

Food and Agriculture Organization. 2001. Global Forest Resources Assessment 2000 Main Report, FAO Forestry Paper 140, Food and Agriculture Organization, Rome.

Groh B, Hübner C, Lendzian KJ. 2002. Water and oxygen permeance of phellem isolated from trees: The role of waxes and lenticels. Planta 215: 794-801. DOI: 10.1007/s00425-0020811-8.

Meehl GA, Arblaster JM. 2003. Mechanisms for projected future changes in south Asian monsoon precipitation. Climate Dynamics 21: 659-675. DOI: 10.1007/s00382-003-0343-3.

Pfautsch S, Renard J, Tjoelker MG, Salih A. 2015. Phloem as capacitor: Radial transfer of water into xylem of tree stems occurs via symplastic transport in ray parenchyma. Plant Physiology 167: 963-971. DOI: 10.1104/pp.114.254581.

Steppe K, De Pauw DJW, Lemeur R, Vanrolleghem PA. 2006. A mathematical model linking tree sap flow dynamics to daily stem diameter fluctuations and radial stem growth. Tree Physiology 26: 257-273. DOI: 10.1093/treephys/26.3.257.

Steppe K, Sterck F, Deslauriers A. 2015. Diel growth dynamics in tree stems: Linking anatomy and ecophysiology. Trends in Plant Science 20: 335-343. DOI: 10.1016/j.tplants.2015. 03.015 .

Tanaka K, Tanaka N, Matsuo N, Tantasirin C, Suzuki M. 2017. Impacts of irrigation on the deciduous period of teak (Tectona grandis) in a monsoonal climate. Canadian Journal of Forest Research 47: 1193-1201. DOI: 10.1139/ cjfr-2017- 0122.

Yoshifuji N, Kumagai T, Tanaka K, Tanaka N, Komatsu H,
Suzuki M, Tantasirin C. 2006. Inter-annual variation in growing season length of a tropical seasonal forest in northern Thailand. Forest Ecology and Management 229: 333339. DOI: 10.1016/j.foreco.2006.04.013.

Yoshifuji N, Komatsu H, Kumagai T, Tanaka N, Tantasirin C, Suzuki M. 2011. Interannual variation in transpiration onset and its predictive indicator for a tropical deciduous forest in northern Thailand based on 8-year sap-flow records. Ecohydrology 4: 225-235. DOI: 10.1002/eco.219.

Yoshifuji N, Igarashi Y, Tanaka N, Tanaka K, Sato T, Tantasirin C, Suzuki M. 2014. Inter-annual variation in the response of leaf-out onset to soil moisture increase in a teak plantation in northern Thailand. International Journal of Biometeorology 58: 2025-2029. DOI: 10.1007/s00484-013-0784-2.

Zweifel R, Häsler R. 2000. Frost-induced reversible shrinkage of bark of mature sub alpine conifers. Agricultual and Forest Meteorology 102: 213-222. DOI: 10.1016/S0168-1923(00) 00135-0.

Zweifel R, Item H, Häsler R. 2000. Stem radius changes and their relation to stored water in stems of young Norway spruce trees. Trees 15: 50-57. DOI: 10.1007/s004680000072.

Zweifel R, Zimmermann L, Newbery DM. 2005. Modeling tree water deficit from microclimate: An approach to quantifying drought stress. Tree Physiologist 25: 147-156. DOI: 10.1093/TREEPHYS/25.2.147.

Zweifel R, Steppe K, Sterck FJ. 2007. Stomatal regulation by microclimate and tree water relations: Interpreting ecophysiological field data with a hydraulic plant model. Journal of Experimental Botany 58: 2113-2131. DOI: 10.1093/jxb/ erm050.

Zweifel R, Haeni M, Buchmann N, Eugster W. 2016. Are trees able to grow in periods of stem shrinkage? New Phytologist 211: 839-849. DOI: 10.1111/nph.13995. 